\title{
Perceiving Quality of Life in Modern Urban Space: Regional Aspect
}

\author{
Anastasiya Babayeva ${ }^{1}$, Evgeny Zakablukovskiy ${ }^{1}$, Tatiana Smetanina $^{1}$, Natalia Shmeleva ${ }^{1}$, \\ Natalia Shilovskaia ${ }^{1, *}$ \\ ${ }^{1}$ Nizhny Novgorod State Pedagogical University, Ulyanov st. 1, Nizhny Novgorod, 603001, Russia
}

\begin{abstract}
The article discusses the problem of modern urban space planning, taking an individual Russian region (Nizhny Novgorod) as an example. The authors argue that neither the policy nor the mentality of government authorities and professionals in the field of architecture can ignore the habits, needs, expectations and views of city residents regarding the best comfortable urban space layout. A sociological survey conducted in Nizhny Novgorod has shown that a modern city dweller's priorities include quality education, access to culture, visual uniqueness of the city and aesthetisation of its space (referring not only to the historic center but also to the residential district areas) that should define modern urban planning strategies. Various forms of social alienation caused by improper structuring of urban space are considered a problem for a modern Russian region: leisure isolationism, discomfort from perceiving residential district areas as periferic with simultaneously preferring virtual space to the physical urban one. In conclusion, recommendations for setting up urban environment layout are offered to urban planners.
\end{abstract}

\section{Introduction}

The task of organizing urban space wisely has probably as many solution options as there were attempts to create a model of ideal living arrangement in the world culture history. The theoretical comprehension and architectural 'materialization' of these diverse views take place in the framework of the new European cultural paradigm. However, modern researchers have come to paradoxical and disappointing conclusions: 'the interaction of three very strong lines in modern thinking - the utopian, project-oriented and architecture-driven ones - led not so much and not only to mutual enrichment and strengthening of these lines of thought as to their emasculation and even profanity' [1].

The collapse of the socialist experiment in the late $\mathrm{XX}^{\text {th }}$ century has also played a significant role in losing the utopian ideals by the architecture. The realities of modern Russian cities illustrate a fait accompli: 'the architectural utopia of the $\mathrm{XX}^{\text {th }}$ century has died, leaving behind only architectural imagination alien to any social ambitions' [2].

A fundamentally different approach to urban space planning talks about proceeding from the requests, expectations and perceptions of the city residents themselves. In the

\footnotetext{
*Corresponding author: shilovskaya-nata@mail.ru
} 
second half of the $\mathrm{XX}^{\text {th }}$ century ideas have come up suggesting that when the habits and needs of real people (who form local communities) are ignored, it may deny the viability of any urban project. These settings of the American 'new urbanism' have greatly influenced modern policy and thinking of municipal authorities and professionals in the field of architecture [3].

Unfortunately, the projects aiming to change the living space of the modern Russian cities, especially the provincial ones, rarely pay attention to the views of the residents themselves about the quality of their life. Meanwhile, studying the degree of life satisfaction, or subjective well-being, becomes increasingly topical today. This factor, along with objective statistics, plays a very important role in determining the quality of life.

L. Belyaeva has performed an interesting comparative analysis of the quality of life in various Russian regions, taking into account how residents themselves assess various aspects of their existence. Her measurement of life quality includes such components as the living standard, immediate social environment quality, the quality of ecology and social well-being [4]. In general, Russian-language publications on the quality of life often put the emphasis on social and economic parameters only. However, the cultural factor is of no less importance in solving this problem. The World Health Organization treats the quality of life as people's perception of their life position depending on their cultural characteristics and value systems and in relation to their goals, expectations and standards.

The many facets of this research subject (the quality of life of modern citizens) determines the interest of scientists from many different areas - the economists, sociologists, ecologists, psychologists, culture experts, architects, specialists in social work and urban agriculture.

There are ongoing active discussions in the Western Hemisphere regarding the participation of classical scholars in defining the logic of urban space development [5]. The issues of moral dimensions of urban planning or the problems of human existential security go beyond the competence of economists and engineers. We are talking about the problems that are associated with the analysis of co-participation, organic involvement of a human being in the city space.

\section{Research Objectives}

A project of social and cultural research (undertaken in 2014-2015) - where an interdisciplinary approach was attempted - has studied the quality of life of Nizhny Novgorod residents as well as their satisfaction with the urban environment. The study focus was aimed at analyzing the subjective experience and perception of the cultural city space by the citizens.

Nizhny Novgorod is a large city but not a metropolis, so it could serve as a good example of a modern Russian city. The relevance of analysis of provincial culture and the cultural contexts of the everyday life of citizens, has determined our choice of the research object.

The research objectives included identifying the hierarchy of cultural needs of citizens and, accordingly, the demand volume for the above urban infrastructure objects. Both specific self-sentiment of certain social groups as well as subjective self-appraisal of someone's personal level of well-being, are of interest. How big is the need for objects of religious character, which ethnical and religious groups feel dissatisfied in this area of cultural life? How big is the demand for the secular culture facilities? What determines usage intensity of these objects? How satisfied are the residents with the overall condition and layout of urban space and, more importantly, with the chances to influence the process of reconstruction of that space. 


\section{Results}

Religious renaissance, actualization of national identity and local traditions, increased migration flows, all these factors would seem to stimulate the need to expand the number of cultural institutions of ethnical and confessional character. Many Russian cities and rural settlements follow the path of saturating the micro-environment with such objects (churches, mosques, religious cultural and recreational centers and educational institutions). However, the study of cultural needs of Nizhny Novgorod residents shows mixed results.

On the one hand, most of the residents identify themselves as believers. Traditional and religious holidays remain to play an important role in Nizhny Novgorod residents' life: those are regularly observed by more than $55 \%$ of the respondents. But today ethnical and cultural identity is becoming more and more important, not the confessional one. The religious meaning of the holiday gives way to the entertaining one. The popularity of mass entertainment events like folk art fairs associated with the holidays is very high. The locations assigned for those are few and usually of temporary nature. Located downtown, they require setting up additional public transportation as well as changes to its routes. These and many other problems remain unresolved. The disparity between residential and central districts is perceived by residents as acute. Nizhny Novgorod residents' minds partially associate ethnic and cultural themes with the issues of urban improvement and with mass entertainment events.

A very small number of citizens felt that increasing attention of the government agencies to ethnic and religious aspects is important for securing residential comfort in the urban space. For example, only $20.8 \%$ of respondents, regardless of their religious and national identity, pointed out that creating conditions for the comprehensive development of national communities is an important task for the municipal authorities. The residents of the region considered this topic much less important than urban improvement $(48.5 \%)$ or improving additional education options for children and adults $(46.5 \%)$ or increasing the number of theatres, museums, concert halls, [art] studios and other places for cultural activities. The hierarchy of the most important culture topics that determine the quality of life in the urban space is as following: quality education $(53.2 \%)$, democratic values $(51.4 \%)$, science progress $(43 \%)$, comprehensive development of culture $(41.5 \%)$. The value of science, education, secular culture retains its relevance for modern Russians while the inaccessibility of the above is perceived by them as violation of their rights. By the way, a special discontent of Nizhny Novgorod residents is caused by the aesthetic appearance of the city and by limited access to decision-making process for its ordinary citizens regarding architectural changes of the new city construction areas or individual buildings. For example, $53.3 \%$ of respondents consider themselves to be fully infringed while $38.9 \%$ consider themselves as partially infringed in this relationship.

At first glance there is a strange conflict of ideals, expectations and actual leisure structure of Nizhny Novgorod residents [6]. An analysis of the most popular forms of spending their spare time shows that passive consumption of finished cultural products located within walking distance is preferred. The living space of citizens narrows significantly. Work and private life - family, close circle of friends, dacha (summer retreat house) visits absorb most of their time. Social and political activism, cultural and (socially) meaningful creative work are the least popular leisure forms. The statistics for the last year are disappointing: $81.8 \%$ of Nizhny Novgorod residents did not visit a library even once, $65.3 \%$ did not go to a theater, $75.8 \%$ - to a museum, $77 \%$ missed any educational tours; festivals are not popular either $(72.5 \%)$. The low level of demand for these cultural sphere segments is not so much connected with their 'archaism'. The fundamental factors in this case are their geography and pricing. A low-income provincial resident perceives cultural and leisure domains as 'luxury'. 
Modern researchers have identified three types of leisure practices - simple, educational and active, stressing that 'active leisure practice as consumption style parameter starts only if the expansion of the leisure preference range occurs at the expense of outdoor types of cultural, entertaining, social or other types of activity' [7]. The consumption style of cultural values determines the modern Russian lifestyle. When studying the specifics of the Russian middle class, N. Tikhonova rightly points out that 'leisure is not just free time remaining after work. It is the ability to make someone's life brighter and richer which is directly related to such an important sociological concept as the quality of life $<\ldots>$ satisfaction with leisure is an important indicator ... of the social well-being of different social groups and has a major influence on their frame of reference' [8].

\section{Discussion}

Nizhny Novgorod as a metropolis is a multicultural object that is open to attracting new people and new areas where 'the space of flows has taken over the logic of the space of places' [9]. This situation, as it would seem, should result in reconfiguring parts of the urban environment and in leveling traditional center/outskirts binary, while a citizen's attitude should embed the idea of the physical space 'collapse', so that the term 'distance' becomes irrelevant at all. However, the citizens continue to feel acute discomfort caused by the close/far binary opposition that is present in the urban cultural space. At the same time, the reality of the 'geographical distance' is taken into account less and less: the downtown inhabitants as well as the residential district dwellers prefer virtual structures to the 'real', the physical ones.

Even when the physical distance (or its perception) is still present, social practices of Nizhny Novgorod develop new forms of alienation. The trend toward social isolationism in the leisure sector (or even wider, in the Lebenswelt), which the citizens demonstrate, should be regarded as a global one. This is a reaction to technical and cultural expropriation and delocalization that happen in urban planning sphere, too. A modern metropolis viewed as a network of spaces is devoid of its integral image 'readability' [10], resulting in the collapse of both its age-old categorization and clear separation of its physical structure [11]. It is worth noting the loss of visual uniqueness as one of the possible consequences of big cities' development (Nizhny Novgorod has not escaped this fate) which is actually perceived quite painfully by its citizens. 'Genius loci' - a specially organized and canonized public space enables a person to feel emotional movement while perceiving the environment. The large number of associations generated by the 'genius loci' plays an important role in the process of social identification.

A shopping center combining a huge number of functions is now a new focus of life in a metropolis where the reflexive subject gets into a situation of a new kind of home-less-ness by radically rejecting the opportunity of being closed to decisions [12]. This is an extremely uncomfortable state of existential basis-less-ness. The home-less-ness of a human being of the previous era was defined by neutralization of a vertical vector, while the integrity of the horizontal profile was kept intact. The annihilation of absolute senses was partly offset by the clarity of fixed social dimensions and by the stability of external locations: the location fixes and protects a value whereas the space envelops and absorbs it. The diffusion and universalization of 'the public' (viewed as an abstract term), the difficulty of implementing primary identities (national and religious) in the multicultural environment of the modern metropolis explicitly accentualizes the geographic aspect of searching a reference point when constructing a personal world - namely the 'home' location.

All of this makes modern metropolis a field full of existential, political and cultural risks. Thus, the issues of urban planning relate not only to the functionality of buildings, streets and avenues, but also to setting up conditions of forming the subjectivity. The 
transformational logic of the modern urban cultural space which is fluctuating and intermittent, consisting of interferences and layers of various kinds, produces a situation which is far from being comfortable for a person living there.

\section{Conclusions}

The research results let us offer several recommendations for urban planners. It would expand the possibilities of designing the urban environment, able to conduct an active dialogue with a citizen and becoming more comfortable: 1) paying maximum attention to architectonic coordinate system, which, on the one hand, contributes to functionally separating various zones but, on the other hand, arranges these parts into a holistic unity; 2) working on producing localities as sets of identities and differences that are actualized situationally; 3) regularly monitoring satisfaction of citizens with the logic of urban space changes and considering their needs when designing urban development projects.

\section{Acknowledgements}

This publication has been made possible through the research project No. 14-13-52002 supported jointly by RHSF and Nizhny Novgorod region.

\section{References}

1. A. G. Rappaport, On a Series of Articles entitled 'Utopia in the Evolution of Architectural Design' by Pyotr Vladimirovich Kapustin / http://archvuz.ru/2011_4/1.

2. A.V. Ikonnikov, The Architecture of the $\mathrm{XX}^{\text {th }}$ Century. Utopias and reality. The History of Architectural Utopias, V.1. Moscow, 2001-2002.

3. J. Jacobs, The Death and Life of Great American Cities. New-York, Random House, 1963.

4. L. A. Belyaeva, Level and Quality of Life. Problems of Measurement and Interpretation, Soc. Research, V.1, 2009.

5. Sh. Epting, Intra-disciplinary Research as Progress in Philosophy: Lessons from Philosophy of the City http://www.academia.edu/20226444/Intradisciplinary_Research_as_Progress_in_Philo sophy_Lessons_from_Philosophy_of_the_City.

6. T. Smetanina, A. Babayeva, A. Spassky, Provincial context as an object sotsiokulturnogo analysis // Bulletin of the University of Minin 2014. No. 3 http: //vestnik.mininuniver.ru/reader/search/provintsialnyy-kontekst-kak-predmetsotsiokulturno/

7. S. A. Ilyinykh, The Consumption Style: a Study of the Russian Leisure Practices, Theory and Practices of Social Development, V. 3, 2016.

8. N. E. Tikhonov, Urban Middle Class in Modern Russia: Analytical Report of the Institute of Sociology, Moscow, 2006.

9. M. Castells, The Rise of the Network Society, Cambridge, MA, Blackwell Publishers, 1996.

10. C. Boyer, CyberCities: Visual Perception in the Age of Electronic Communication, New York, Princeton Architectural Press, 1997.

11. P. Virilio, The Lost Dimension, New York, Semiotext(e), 1991.

12. U.Beck, Risk Society: Towards a New Modernity, London, Sage, 1992. 